\title{
Observation of the ionospheric storm of October 11, 2008 using FORMOSAT-3/COSMIC data
}

\author{
I. E. Zakharenkova ${ }^{1,2}$, A. Krankowski ${ }^{2}$, I. I. Shagimuratov ${ }^{1}$, Yu. V. Cherniak ${ }^{1}$, \\ A. Krypiak-Gregorczyk ${ }^{2}$, P. Wielgosz ${ }^{2}$, and A. F. Lagovsky ${ }^{3}$ \\ ${ }^{1}$ West Department of IZMIRAN, Kaliningrad, Russia \\ ${ }^{2}$ Geodynamics Research Laboratory, University of Warmia and Mazury, Olsztyn, Poland \\ ${ }^{3}$ Immanuel Kant State University of Russia, Kaliningrad, Russia
}

(Received June 11, 2010; Revised March 16, 2011; Accepted June 24, 2011; Online published July 27, 2012)

\begin{abstract}
The electron density profiles retrieved from the COSMIC radio occultation measurements were examined in order to estimate the possibility of its use as additional data source to study changes in electron density distribution occurred during ionospheric storms. The ionosphere behaviour during moderate geomagnetic storm which occurred on October 11, 2008 was analysed. The short-duration positive effect was revealed distinctly in GPS TEC and ionosonde measurements. For the European mid-latitude region it reached the factor of 2 or more relative to the undisturbed conditions. COSMIC data were analyzed and their validity was tested by comparison with ground-based measurements. It was shown the good agreement between independent measurements both in quiet and disturbed conditions. Analysis of COSMIC-derived electron density profiles revealed changes of the bottom-side and topside parts of the ionosphere.
\end{abstract}

Key words: Radio occultation, COSMIC, GPS, ionosphere.

\section{Introduction}

The radio occultation (RO) technique using GPS signals collected by Low Earth Orbit (LEO) satellites has been proven to be a promising technique to retrieve accurate profiles of the ionospheric electron density with high vertical resolution on a global scale. This technique was firstly applied at MicroLab 1 satellite, also known as OrbView 1, launched on April 3, 1995. That mission payload had an atmospheric monitoring instrument (GPS/MET). The analysis of GPS/MET sensor data had shown that the signals from the GPS satellite constellation intended for precise navigation and positioning can also be used to provide important atmospheric data. Besides the main goal of weather monitoring, it has also been possible to use GPS/MET sensor for sounding of the ionosphere from the orbit altitude to the Earth' surface and retrieve one-dimensional profiles of ionospheric electron density from measurements of ray-path bending angle or TEC (Hajj and Romans, 1998). Following the successful GPS/MET experiment, similar satellite missions, such as CHAMP (Germany), SAC-C (Argentina), GRACE (US and Germany), and TerraSAR-X (Germany), were carried out. A number of relevant publications were based on these mission measurements and problems of data processing and validation (e.g., Schreiner et al., 1999; Hernandez-Pajares et al., 2000; Jakowski et al., 2002; Colomb et al., 2004; Garcia-Fernandez et al., 2005).

However, the existing satellites performing radio occul-

Copyright (C) The Society of Geomagnetism and Earth, Planetary and Space Sciences (SGEPSS); The Seismological Society of Japan; The Volcanological Society of Japan; The Geodetic Society of Japan; The Japanese Society for Planetary Sciences; TERRAPUB.

doi: $10.5047 /$ eps.2011.06.046 tation experiments are mainly solo-satellite missions, and therefore, a long observation time is required to complete global coverage. FormoSat-3 (Taiwan's Formosa Satellite Mission \#3) / COSMIC (Constellation Observing System for Meteorology, Ionosphere and Climate) is a joint scientific mission of Taiwan and the U.S.A., which was launched on April 15, 2006. The mission placed six small micro-satellites into six different orbits at 700 800 kilometers above the earth surface. The orbit inclination is $72^{\circ}$. Each microsatellite has a GPS Occultation Experiment (GOX) payload to operate the ionospheric RO measurements. Depending on the state of the constellation COSMIC has been producing between 1,500-2,500 good soundings of the ionosphere and atmosphere per day, uniformly distributed around the globe. This number of RO is much greater than ever before. The total number of the ionospheric occultations for years 2006-2009 is over 2,000,000 (more than 50,000 profiles per month). The previous missions were able to produce only 4,000-6,000 RO profiles per month (only several hundred per day). So, COSMIC data can make a positive and considerable impact on global ionosphere studies providing essential information about vertical distribution of the electron density and particularly over regions that are not accessible with ground-based instruments such as ionosondes and dual frequency GPS stations.

This paper focuses on applications of the radio occultation observations performed by the GOX instruments and the preliminary scientific results of ionospheric studies by using RO electron density observations. Our purpose was to illustrate the possibility of using RO measurements as additional data source to study changes in electron density 

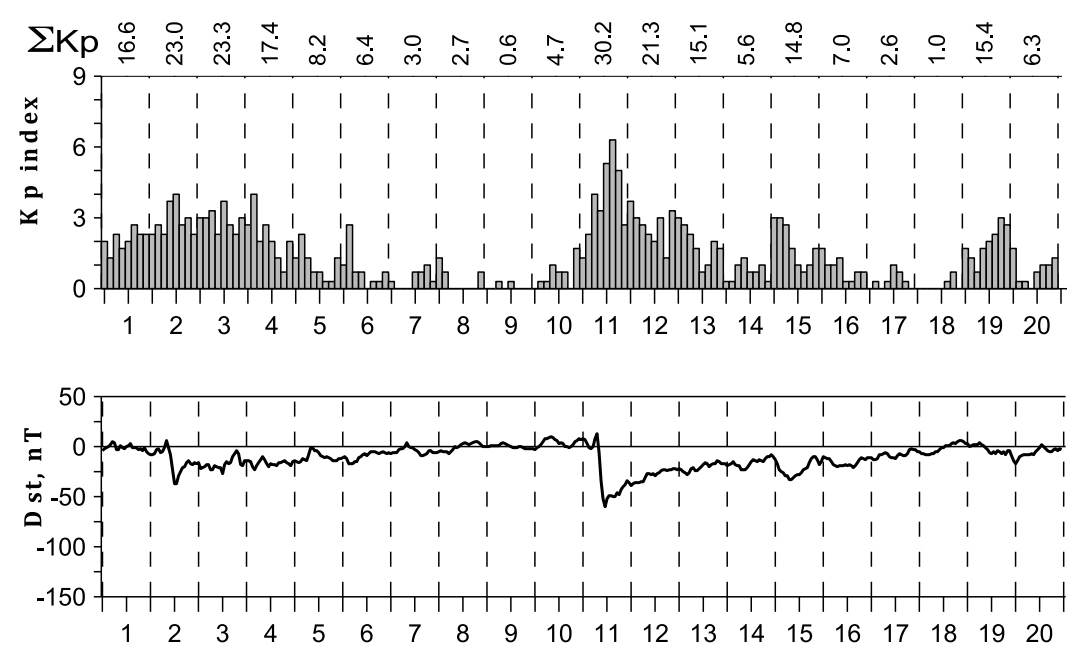

Fig. 1. Variations of $K_{\mathrm{p}}$ and $D_{\mathrm{st}}$ indices during October 1-20, 2008.

distribution occurred during ionospheric storms. The ionosphere behaviour during moderate geomagnetic disturbance which occurred on October 11, 2008 was analyzed. A relatively weak but isolated geomagnetic disturbance was characterized by the well-pronounced positive effect observed in the ionosphere at the dayside. Figure 1 presents the variations of geomagnetic activity indices $\left(K_{\mathrm{p}}, D_{\mathrm{st}}\right)$ during October $1-20,2008$. The $D_{\text {st }}$ index reached the minimum of $-60 \mathrm{nT}, K_{\mathrm{p}}$ sum was about 30 . This disturbance occurred during a period of very low solar activity.

\section{Database}

\subsection{COSMIC RO data}

Since May 2006 the retrieved $N_{\mathrm{e}}$ profiles have been available from the Taiwan Analysis Center for COSMIC (TACC, http://tacc.cwb.gov.tw/en/) and the COSMIC Data Analysis and Archive Center (CDAAC, http://cosmicio.cosmic.ucar.edu/cdaac/). Generally COSMIC can perform over 1,500-2,500 RO measurements per day, and for more than $70 \%$ of the $\mathrm{RO}$ measurements it is possible to successfully retrieve the $N_{\mathrm{e}}$ profiles, one of the most important products for space weather and ionospheric science. At CDAAC, the ionospheric profiles are retrieved by the Abel inversion from TEC along LEO-GPS rays. Detailed description of CDAAC data processing and $N_{\mathrm{e}}$ profile retrieval method can be found in Kuo et al. (2004), Syndergaard et al. (2006). We used the second level data provided by CDAAC - 'ionprf' files containing information about ionospheric electron density profiles. COSMIC sounding points during a 24-hour period have a rather good global distribution. For this study, occultations with tangent points of the signal ray path within the limits of the European region were selected. The path of the tangent point during the occultation is named the occultation trace. Depending on the relative COSMIC-GPS satellite constellation the data coverage changes permanently. Usually the total number of occultation traces in the European region is about 35-50 per day. According to the information provided by CDAAC a small part of the COSMIC electron density profiles are affected by cycle slips in the GPS phase data. In some cases this results in obviously distorted profiles, whereas in other cases the errors due to cycle slips are more subtle. For this study we focused on the manual checking and painstaking screening of initial data. The detected distorted $\mathrm{RO}$ profiles were removed from analysis.

As COSMIC RO observations have a rather dense global distribution, they are potentially able to provide threedimensional (3-D) ionosphere images that allow better understanding of the ionospheric structure and dynamics. Several recent papers demonstrate success in construction of global 3-D ionospheric maps to study the ionospheric seasonal effects (Lin et al., 2009; Tsai et al., 2009). In this case global mapping of the ionospheric electron density was carried out by using spherical harmonic $(\mathrm{SH})$ analysis. $N_{\mathrm{e}}$ data corresponding to the various altitude ranges from 150-200 to $400-450 \mathrm{~km}$ with 2 -hour resolution were selected. The distribution of $N_{\mathrm{e}}$ over the globe was represented with a spherical harmonic expansion up to a maximum degree and order values equal to 10, as shown in Eq. (1).

$$
\begin{aligned}
N_{\mathrm{e}}(\varphi, \lambda)= & \sum_{n=0}^{10} \sum_{m=0}^{n} P_{n m}(\sin \varphi) \\
& \times\left(a_{n m} \cos (m \lambda)+b_{n m} \sin (m \lambda)\right)
\end{aligned}
$$

where $\varphi, \lambda$ are geographic latitude and longitude, $P_{n m}$ are the normalized associated Legendre functions; and $a_{n m}$ and $b_{n m}$ are the SH coefficients which were derived using COSMIC observations. Detailed description of SH application to the RO data mapping can be found in Tsai et al. (2009).

\subsection{DIAS data}

Ionosondes are typically used as diagnostic tools important for calibrating other more complicated observation methods such as incoherent scatter radar, satellite beacon tomography and radio occultation. Vertical sounding measurements by ground based ionosondes provide a precise determination of the bottom side electron density profile, but they are incapable to deliver information about the topside part of electron density profile (above the height of $F_{2}$ layer peak). Therefore, the complete electron density profile in the ionosonde measurements consists of a measured bottomside and a modeled topside part. In order 


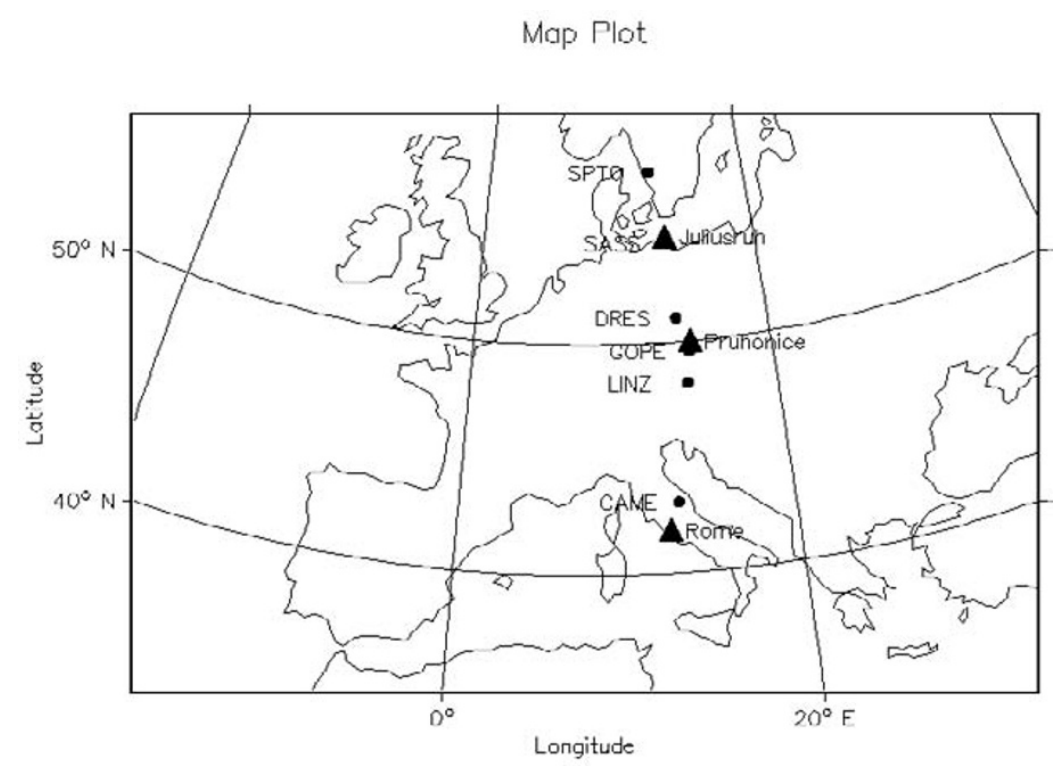

Fig. 2. Geographical position of GPS stations (black circles) and ionosondes (triangles) located closely in the north-south direction.

to validate the reliability of COSMIC data the ionograms, $f_{\mathrm{o}} F_{2}$ values and electron density profiles provided by the European Digital Upper Atmosphere Server (DIAS) were used. The DIAS server (http://www.iono.noa.gr/DIAS) operates since May 2005 and delivers such products as realtime and archive ionograms from all DIAS ionosonde stations, frequency plots and maps of the ionosphere over Europe based on the $f_{0} F_{2}, M(3000) F_{2}$, MUF and electron density parameters (Belehaki et al., 2005). This server collects information from the ionosondes located in Rome, Pruhonice, Juliusruh, Athens, Chilton, Ebre and El Arenosillo. The DIAS ionosonde network is equipped with the DPS-4 ionosondes (except for Ebre and El Arenosillo equipped with DGS-256) produced by the University of Lowell, Massachusetts, United States. On these stations the ARTIST (Automated Real Time Ionogram Scaler with True height) software for ionogram automatic scaling and real-time NHPC with true height inversion are used. The ARTIST system is a very skilled algorithm characterized by high percentage of reliable autoscaled data (Reinisch and Huang, 2001; Reinisch et al., 2005; McNamara, 2006; Galkin et al., 2008). Real-time ionosonde ionograms are scaled by autoscaling program and sent to the server. However, serious autoscaling errors can occur and it is recommended to check the ionosonde data against the ionogram of the same sounding for accuracy. In order to eliminate possible errors introduced by autoscaling we have done manual verification of all involved ionograms using DIAS database.

\subsection{IGS data}

The permanent GPS network provides regular monitoring of the ionosphere on a global scale with high resolution TEC measurements. The TEC data obtained from GPS observations of the IGS (International GNSS Service) network were used to study the ionosphere storm-induced effects in the European region. The methodology described by Baran et al. (1997) was used to restore the daily variation in TEC using the measurements of all satellite passes over the sta- tion within the 24-hour interval. In these calculations the ionosphere is approximated as a thin layer located at a fixed height $(h=400 \mathrm{~km})$. The slant TEC (along the ray) and vertical TEC with first-order approximation can be related by the geometrical factor: VTEC $=$ TEC $\times \cos z^{\prime}$, where $z^{\prime}$ is the zenith angle of the satellite on the layer height. Using this procedure an absolute TEC variation over single station is calculated.

Also in the present investigation, the IGS Global Ionospheric Maps (GIM) of TEC in the IONEX format were used. IONEX data are accessible at the ftp server: ftp://cddis.gsfc.nasa.gov/pub/gps/products/ionex. The GIMs are generated routinely by the IGS community with resolution of $5^{\circ}$ longitude and $2.5^{\circ}$ latitude and temporal interval of 2 hours; one TEC unit (TECU) is equal $10^{16}$ electrons $/ \mathrm{m}^{2}$. In this investigation the final IGS combined GIMs produced by the Geodynamics Research Laboratory of the University of Warmia and Mazury in Olsztyn (GRL/UWM) were used.

\section{Results}

In the case of the October 11, 2008 storm a wellpronounced positive effect was observed during day-time. Though $D_{\text {st }}$ decrease was not so deep, this disturbance lead to a strong TEC enhancement. At middle latitudes of the European region the maximal effect took place near noon, the enhancement of TEC was about $100 \%$. In order to illustrate this positive effect over Europe we select the chain of European ground-based GPS receivers located at different geographic latitudes between $40^{\circ} \mathrm{N}$ and $60^{\circ} \mathrm{N}$ and $13^{\circ}-14^{\circ} \mathrm{E}$ geographic longitude and nearby ionosonde stations. Figure 2 presents the geographical map with positions of selected GPS receivers' chain and ionosondes; taken together they form line with north-south direction. Figure 3 shows daily values of vertical TEC at different latitudes over Europe during October 7-15, 2008. The actual observations are indicated with a solid line and represent the vertical TEC in TECU for GPS stations. For October 

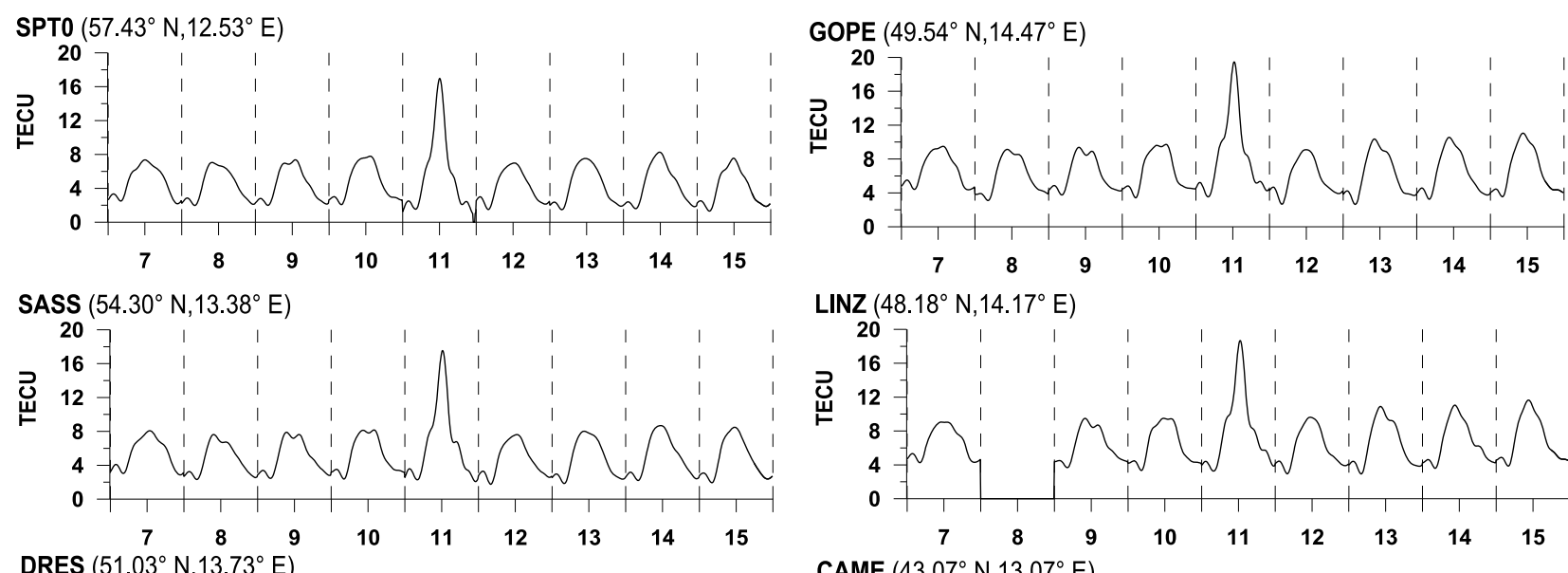

LINZ $\left(48.18^{\circ} \mathrm{N}, 14.17^{\circ} \mathrm{E}\right)$

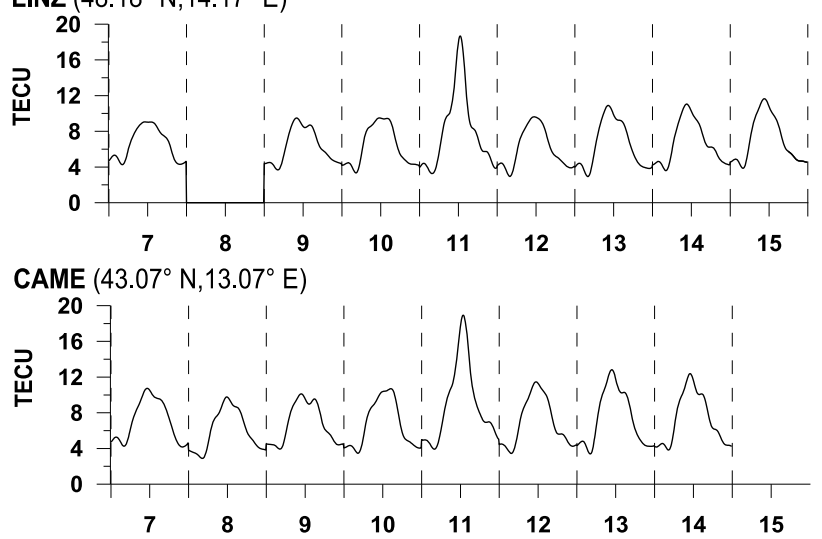

Fig. 3. Daily values of TEC with 10 min resolution over Europe at different latitudes during October 7-15, 2008.

11, 2008 one can observe the considerable enhancement of TEC that reached the factor of 2. This effect was wellpronounced at all stations and has practically the same magnitude for all considered latitudes. The strong TEC increase over European region has rather short duration (11-15 UT) and its amplitude reached the maximum value of 9 TECU (100\% relative to the quiet conditions). This enhancement could be clearly observed in the $f_{\mathrm{o}} F_{2}$ variations over ionosonde stations Juliusruh $\left(54.6^{\circ} \mathrm{N}, 13.4^{\circ} \mathrm{E}\right)$, Pruhonice $\left(50.0^{\circ} \mathrm{N}, 14.6^{\circ} \mathrm{E}\right)$ and Rome $\left(41.9^{\circ} \mathrm{N}, 12.5^{\circ} \mathrm{E}\right)($ Fig. 4$)$. The $f_{\mathrm{o}} F_{2}$ increased from 5.6 to $9.0 \mathrm{MHz}$ during the $3 \mathrm{~h}$ period at Juliusruh and from 5.6 to $8.3 \mathrm{MHz}$ during the $3 \mathrm{~h}$ period at Rome.

The major enhancement of the dayside ionospheric electron density observed at European mid-latitudes during this storm event was assumed as a basis in order to examine the quality of COSMIC RO data and possibility to include them to the joint investigations of the ionospheric response to a geomagnetic disturbance. Firstly, we have to examine the quality of RO-derived $N_{\mathrm{e}}$ profiles by comparing them to ionosonde $N_{\mathrm{e}}$ profiles in quiet and disturbed conditions. COSMIC RO profiles corresponding to the European region within a horizontal cross section of $5^{\circ}$ diameter over three closely located mid-latitude ionosondes (Chilton, Juliusruh and Pruhonice) of DIAS network were selected. As the main point of our interest was $F_{2}$ layer peak, it was analyzed RO profiles with projection of the $F_{2}$ layer maximum close to the ionosonde point. Unfortunately, the number of $N_{\mathrm{e}}$ profiles provided by COSMIC mission is still insufficient to study the daily behaviour of the ionosphere over any specified point and there is no day-by-day reiteration of occultation events over the same region as location of RO profiles depends only on the LEO satellite path and links with GPS satellites. Therefore, it was difficult to find $\mathrm{RO}$ profiles that would provide good time coverage in the vicinity of only one ionosonde. This is why two different

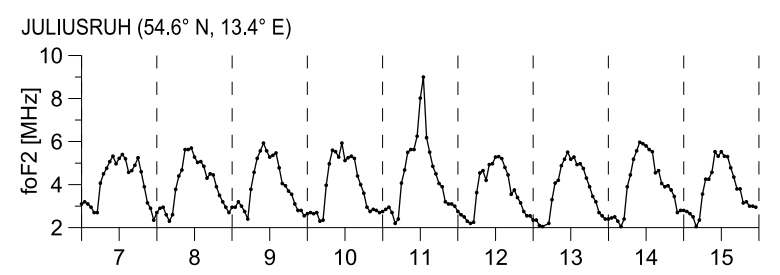

PRUHONICE $\left(50.0^{\circ} \mathrm{N}, 14.6^{\circ} \mathrm{E}\right)$

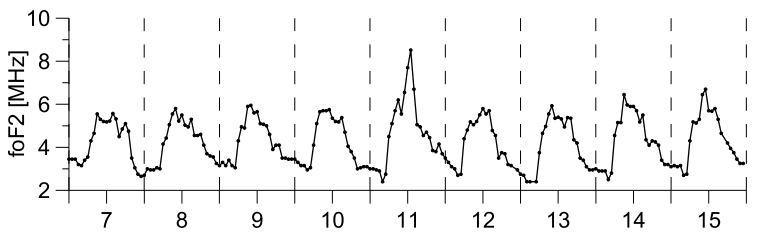

$\operatorname{ROME}\left(41.9^{\circ} \mathrm{N}, 12.5^{\circ} \mathrm{E}\right)$

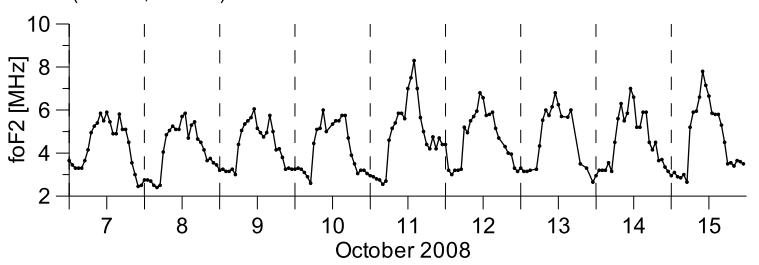

Fig. 4. Daily values of $f_{\mathrm{o}} F_{2}$ with $1 \mathrm{~h}$ resolution over Juliusruh, Pruhonice and Rome during October 7-15, 2008.

ionosonde locations were chosen. For each location, several RO measurements made on quiet and storm dates at the similar UT interval were selected. These restrictions have considerably reduced the number of selected RO profiles, resulted in the choice of RO events close to Chilton $\left(51.5^{\circ} \mathrm{N}, 0.6^{\circ} \mathrm{W}\right)$, Juliusruh and Pruhonice ionosondes. For the day of storm, October 11, 2008, there were selected 30 RO profiles within the limits of European region and only 8 profiles were related to the region of ionosondes' location. For the quiet days of October 9 and 10, 2008 it was available 6 and 5 profiles correspondingly. In that way COSMIC 

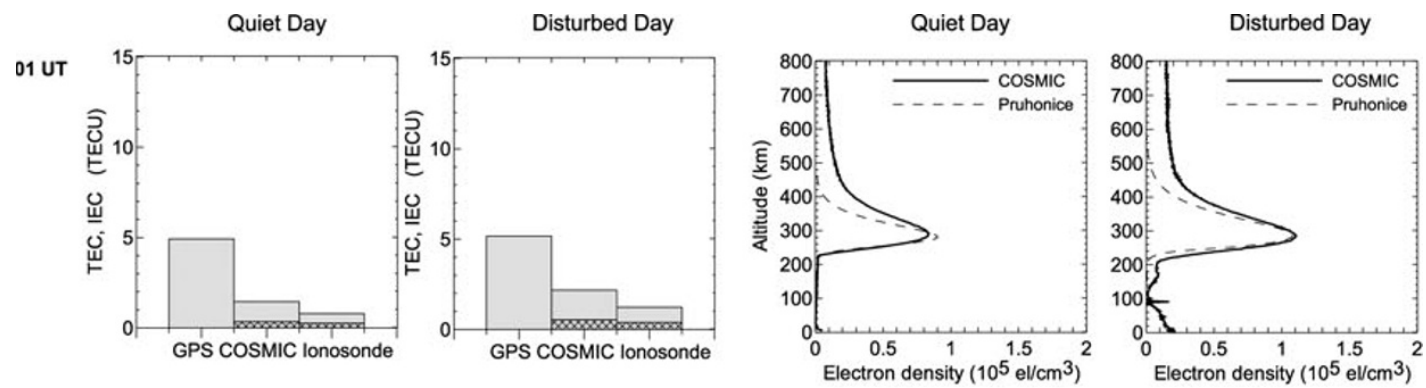

09 UT
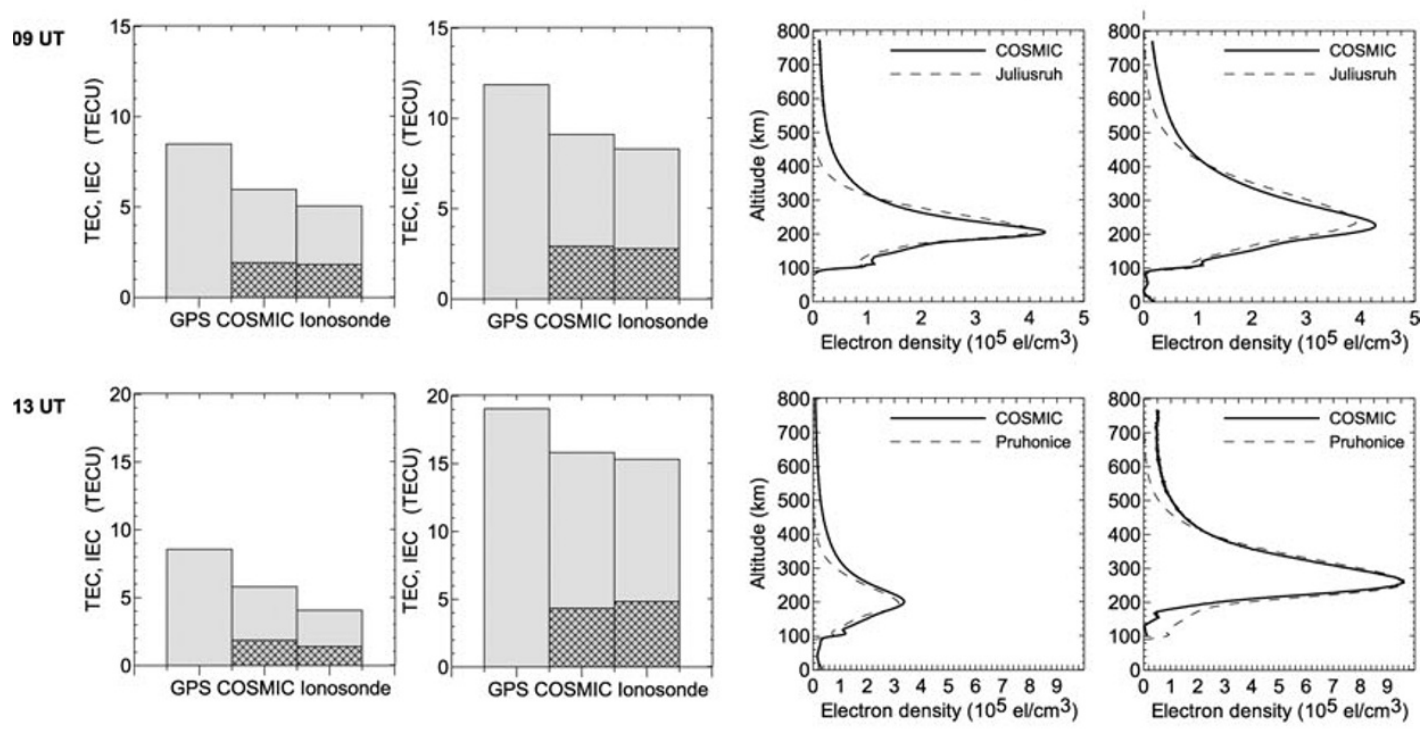

16 UT
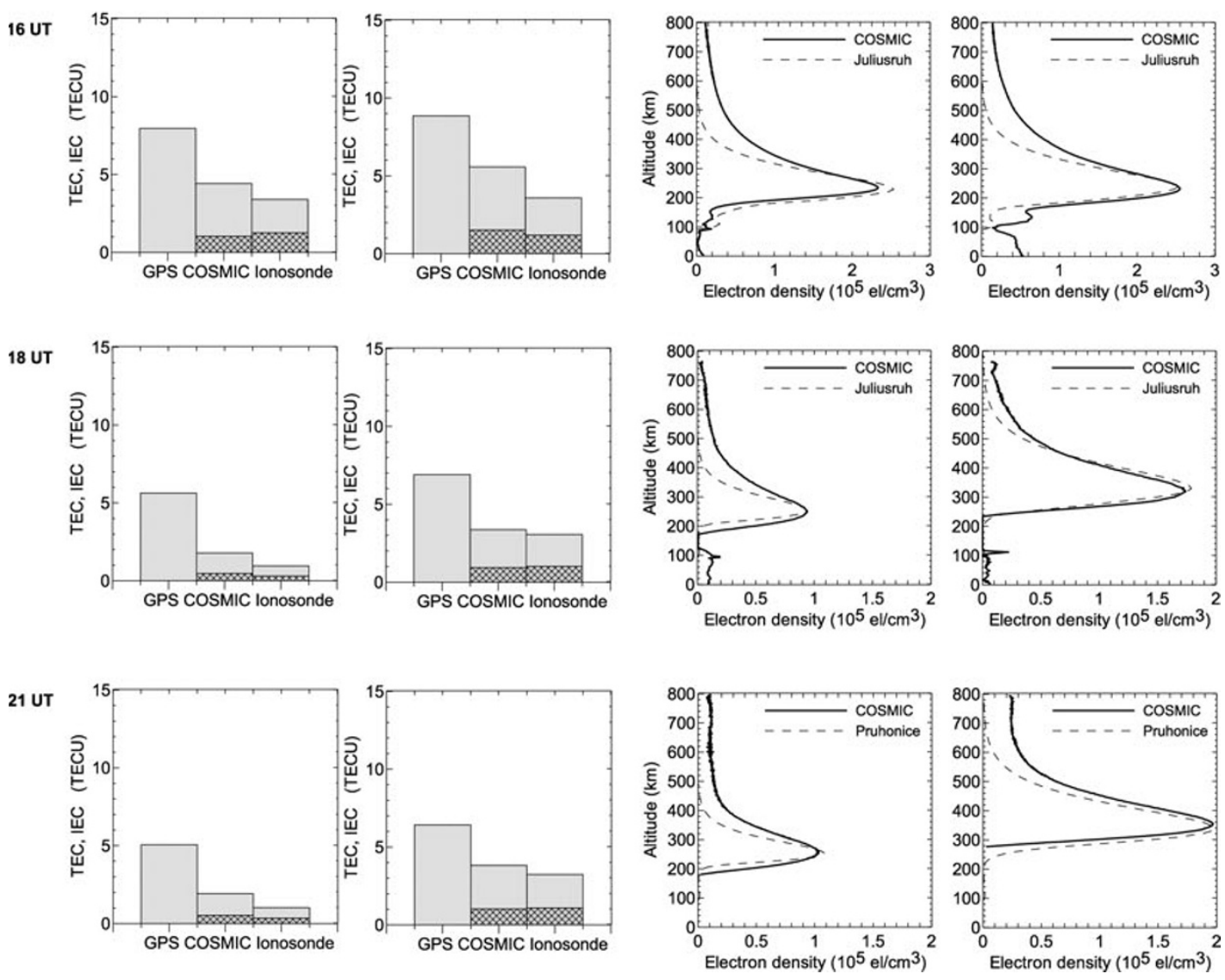

Fig. 5. Comparison of COSMIC and ionosonde electron density profiles (right panels), and GPSTEC measurements with IEC calculated from COSMIC and ionosonde measurements (left panels) for quiet and disturbed days. 
COSMIC RO profiles

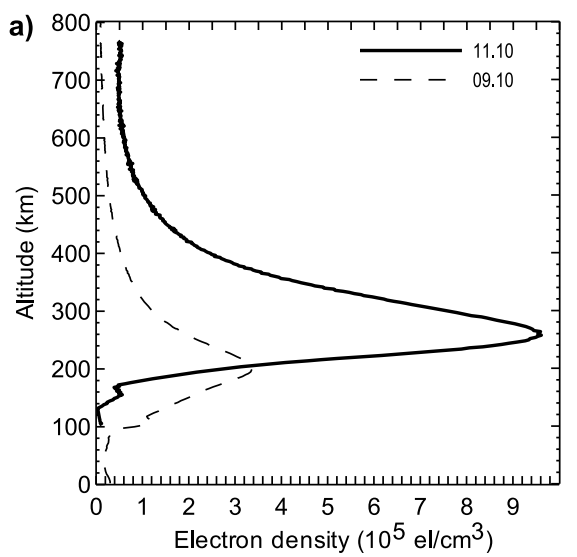

lonosonde profiles

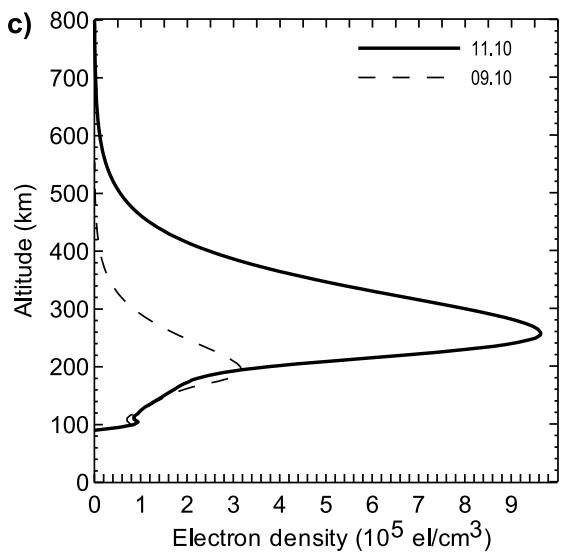

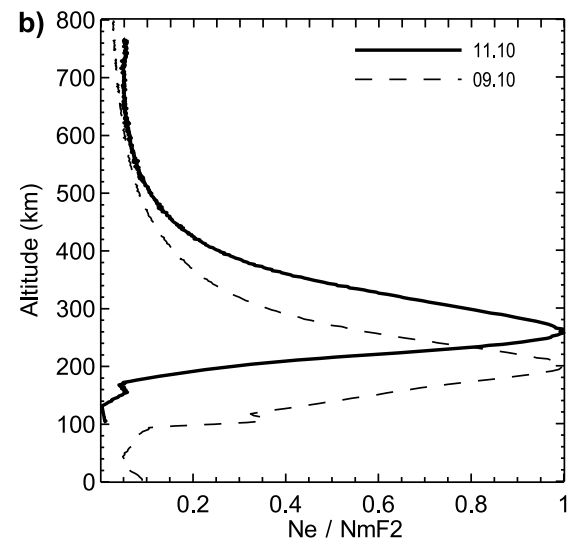

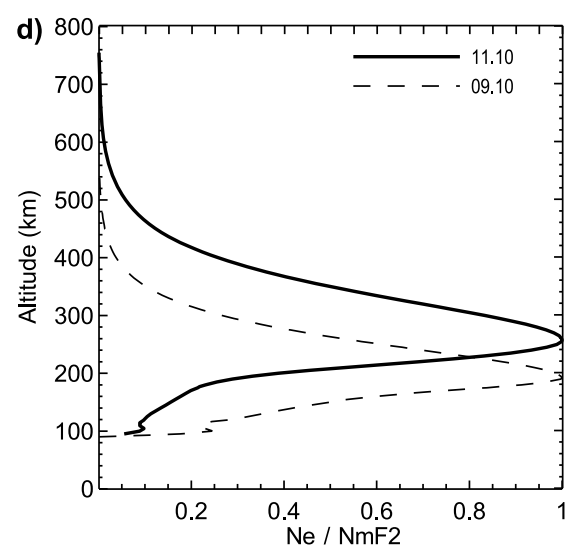

Fig. 6. Comparison of COSMIC electron density profiles at 13 UT on October 9 and 11, 2008. The right graph demonstrates $N_{\mathrm{e}}$ profiles normalized to the $N_{\mathrm{m}} F_{2}$ value. Bottom panel shows the similar comparison of ionosonde $N_{\mathrm{e}}$ profiles.

RO profiles derived on October 11, 2008 (Disturbed day) were compared with electron density profiles derived from the measurements of the nearest ionosonde. Simultaneous RO and ionosonde profiles obtained on October 9-10, 2010 (Quiet day) were analyzed as well. The right panels of Fig. 5 illustrate the comparison of simultaneous COSMIC RO (solid line) and ionosonde (dashed line) electron density profiles. Indicated time corresponds to the temporal interval $\pm 30 \mathrm{~min}$ relative to the given hour of UT. The peak electron densities $\left(N_{\mathrm{m}} F_{2}\right)$ of these profiles show reasonable agreement, the peak heights of the $F_{2}$ layer $\left(h_{\mathrm{m}} F_{2}\right)$ are also comparable. In general, both independent measurements gave rather similar profiles even during the disturbed day. This demonstrates that the RO-retrieved $N_{\mathrm{m}} F_{2}$ and $h_{\mathrm{m}} F_{2}$ are reliable at middle latitudes of European region. The comparison of electron density profiles for quiet and disturbed days indicates essential enhancement of electron density around 13 UT. Figure 6(a) illustrates the evaluation of COSMIC RO profiles registered at 13 UT on quiet and disturbed days. The significant difference between these profiles is clearly seen. Peak electron density increased by a factor of 2.9, height of $F_{2}$ layer maximum was risen by $60 \mathrm{~km}$ in comparison with the quiet day profile characteristics. Also these plots show a decrease in the $F_{1}$ region ionization during the positive storm phase. The large positive effect in $F_{2}$ region accompanied by a negative effect at $F_{1}$ region heights $(\sim 150-200 \mathrm{~km})$ agrees with finding by Buresova et al. (2002) that storm effects at $F_{1}$ region heights at European higher middle latitudes are always negative. However, it must be noted that this effect in $F_{1}$ region is more pronounced in COSMIC-derived electron density profiles (Figs. 6(a) and 6(c)). Comparison of COSMIC and ionosonde-derived profiles corresponded to the moment of 13 UT (Fig. 5) revealed that COSMIC data had the smaller ionization below $200 \mathrm{~km}$. Such differences in the low part of profile can be possible related to the RO geometry and to the remoteness of the corresponded parts of RO trace from the ionosonde location.

In order to estimate the shape of the electron density profiles, the electron density values were normalized to the peak electron density. Figure 6(b) shows the normalized profiles for these days. Figures 6(c) and 6(d) present the same comparison for the ionosonde-derived $N_{\mathrm{e}}$ profiles, which are given as a benchmark data. One can see the increase of $F_{2}$ layer height $(\sim 60 \mathrm{~km})$, but in general, the shape of the profiles near $F_{2}$ region is a very similar for both quiet and disturbed days. These results indicate that the ratio of topside to the bottom-side values of electron content remained practically the same.

In the results presented above only two parameters were compared-the peak electron density (consequently, the critical frequency) and the peak height of the $F$-region. In 


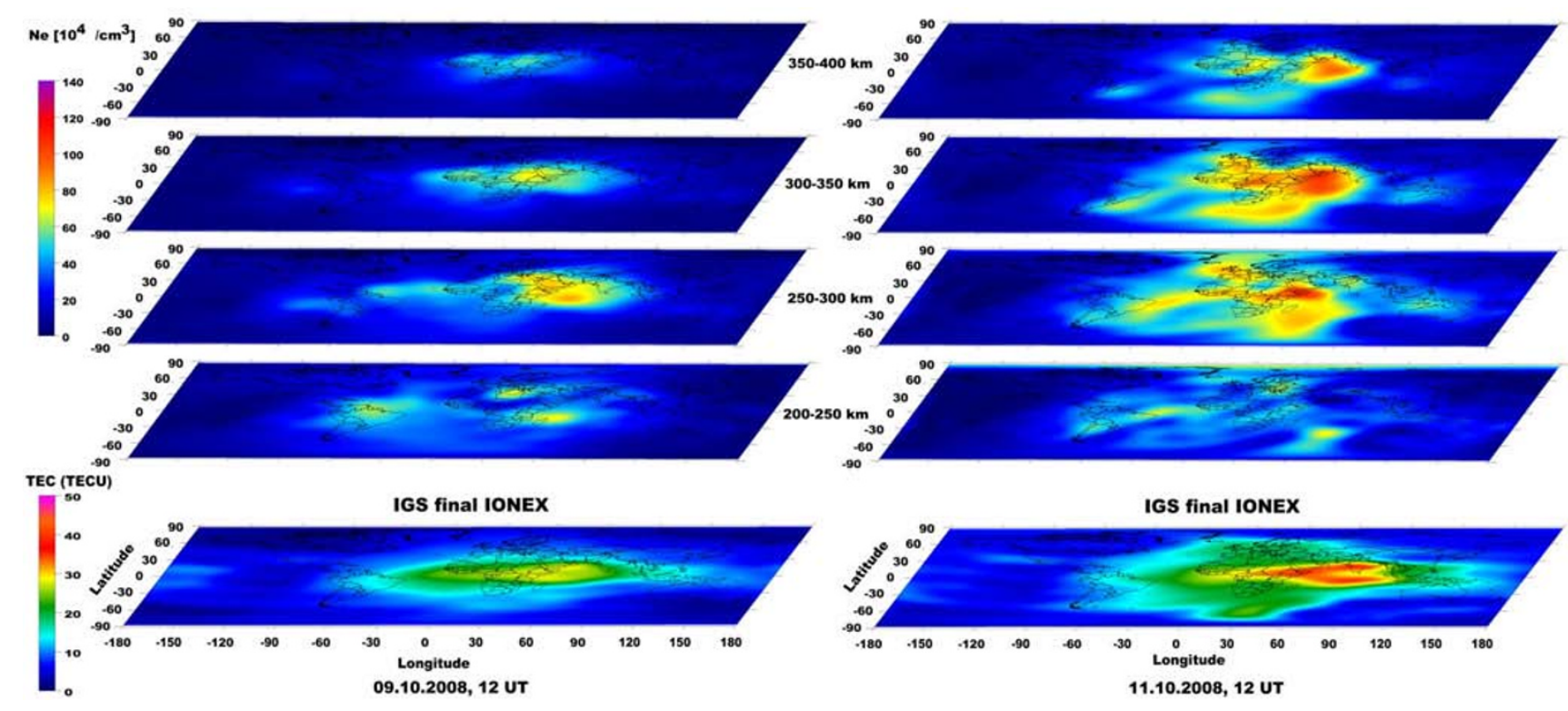

Fig. 7. Global maps of the ionospheric electron density at various altitudes at 12 UT on October 9 and 11,2008 . The bottom panel presents the IGS TEC maps.

order to enlarge this comparison, the ground-based GPS TEC data were added to the analysis. To compare GPS TEC with RO and ionosonde's data these electron density profiles were integrated. In addition, the data integration up to the height of $F_{2}$ layer maximum was carried out. The left panels in Fig. 5 demonstrate the results of these calculations. Each bar graph illustrates GPS TEC, COSMIC and ionosonde IEC (ionospheric electron content). The grey crosshatched bar histogram indicates the electron content up to the height of peak electron density. Hence, it is possible to compare the bottom-side and the topside parts of electron density profiles.

In general, bottom parts of COSMIC and ionosonde data are in a better agreement than topside ones. Practically for all cases the understated values of electron density in the topside part of the ionosonde profiles were observed in comparison with RO profiles. It can be explained by the fact that the topside ionosonde profile is obtained by fitting a model to the peak electron density value, the COSMIC one is obtained from experimental data and can make an important contribution to the investigation of the topside part of the ionosphere. Also, it is necessary to note that GPS TEC values are greater than COSMIC and ionosondederived ones as GPS TEC contains IEC and PEC (plasmaspheric electron content). This procedure can be useful to estimate the contribution of PEC on TEC.

Both TEC and IEC increased significantly for the moment of 13 UT (Fig. 5). GPS TEC increased by a factor of 2.2 in comparison with quiet day value (from 8.6 to 19 TECU). COSMIC-derived IEC increased by a factor of 2.7 and increase of ionosonde-derived IEC reached the factor of 3.7. It is interesting to estimate the proportion of topside and bottom-side parts to the IEC values. For the considered moment of time (13 UT) the ratio between different parts were calculated. It was found out that for quiet day the contribution of the topside part into COSMIC-derived IEC value was about $68 \%$ and the bottom-side part provided
$32 \%$. For disturbed conditions these values were $72 \%$ and $28 \%$, respectively. For the ionosonde-derived values of IEC the topside part was about $66 \%$ of IEC for quiet day and $68 \%$ for disturbed day, bottom-side part-34\% and $32 \%$, respectively. Examining the matter it was found out that in spite of the significant storm-induced enhancement of IEC, the proportion between topside and bottom-side parts remained practically invariable and these parts were increased proportionally by the same factor.

In order to illustrate the possibility of COSMIC data application to the analysis of global scale effects of ionospheric storms the global electron density maps were created based on the globally distributed COSMIC RO profiles. Figure 7 shows electron density maps for different altitude slices corresponding to 12 UT on October 9 and 11, 2008. At the bottom panel of Fig. 7 the global ionospheric maps provided by IGS are presented for the same time. One can clearly see the positive storm-induced effect in electron density on the disturbed day. A considerable enhancement of the spatial scale and magnitude of the equatorial ionization anomaly is observed within the African longitudinal sector at all slices. These graphs visualize the uplifting of $F_{2}$ layer near noon on October 11. The most pronounced effect of the electron density increase occurred at the altitude range of $300-350 \mathrm{~km}$. It is also necessary to note that the considerable $N_{\mathrm{e}}$ increase effect at the altitudes of 350-400 km illustrated the changes in the topside part of the ionosphere.

The day-side enhancement in electron density was observed during geomagnetic disturbance on October 11, 2008. In European region the strong short-term positive effect reached factor of 2 and more relative to the undisturbed conditions. This effect was revealed distinctly both in GPS TEC and ionosonde measurements. COSMIC RO data were analyzed and their validity was tested by comparison with ground-based measurements. The results show the good agreement between independent measurements during quiet and disturbed conditions. Analysis of COSMIC- 
derived $N_{\mathrm{e}}$ profiles over European region demonstrated that for the given ionospheric storm RO was able to provide well-comparable and reliable characteristics of $N_{\mathrm{e}}$ profile such as $N_{\mathrm{m}} F_{2}$ and $h_{\mathrm{m}} F_{2}$. Unfortunately, the number of $N_{\mathrm{e}}$ profiles provided by COSMIC mission is still insufficient to study the daily behaviour of the ionosphere over any specified point. Therefore, COSMIC measurements can be effectively used only as additional data source for analysis and reconstructing of electron density distribution in the ionosphere.

\section{Conclusions}

COSMIC RO measurements were used in the analysis of the ionosphere behaviour during geomagnetic disturbance. It was shown that there is a possibility to complement the ionosphere studies based on the standard ground-based GPS measurements with the information about the vertical electron density distribution retrieved from COSMIC RO measurements. The distinctive feature of this moderate geomagnetic storm was the short duration of the ionospheric effect. This positive effect was revealed distinctly in RO electron density profiles and products based on these dataionospheric electron content and global maps of electron density. The quality of RO profiles was estimated by comparison with the data provided by the ionospheric sounding stations of the European network DIAS. COSMIC RO measurements have several perspective advantages in comparison with the traditional ground-based measurementsglobal distribution of the occultation events and probing of the topside part of the ionosphere. In addition, RO technique based on LEO constellation data gives very valuable information for the ionosphere diagnostics in the areas where ground-based stations do not exist.

Acknowledgments. We acknowledge the Taiwan's National Space Organization (NSPO) and the University Corporation for Atmospheric Research (UCAR) for providing the COSMIC Data. We are grateful to European Digital Upper Atmosphere Server (DIAS) for providing the ionosondes' products and to International GNSS Service (IGS) for GPS Data.

\section{References}

Baran, L. W., I. I. Shagimuratov, and N. J. Tepenitsina, The use of GPS for ionospheric studies, Artificial Satellites, 32(1), 49-60, 1997.

Belehaki, A., Lj. Cander, B. Zolesi, J. Bremer, C. Juren, I. Stanislawska, D. Dialetis, and M. Hatzopoulos, DIAS Project: The establishment of a European digital upper atmosphere server, J. Atmos. Sol.-Terr. Phys., 67(12), 1092-1099, 2005.

Buresova, D., J. Lastovicka, D. Altadill, and G. Miro, Daytime electron density at the F1-region in Europe during geomagnetic storms, Ann. Geophys., 20(7), 1007-1021, 2002.

Colomb, F. R., C. Alonso, C. Hofmann, and I. Nollmann, SAC-C mission, an example of international cooperation, Adv. Space Res., 34(10), 2194 2199, 2004.

Galkin, I. A., G. M. Khmyrov, A. V. Kozlov, B. W. Reinisch, X. Huang, and V. V. Paznukhov, The ARTIST 5, in Radio Sounding and Plasma Physics, AIP Conf. Proc., 974, 150-159, 2008.

Garcia-Fernandez, M., A. Saito, J. M. Juan, and T. Tsuda, Threedimensional estimation of electron density over Japan using the GEONET GPS network combined with SAC-C data and ionosonde measurements, J. Geophys. Res., 110, A11304, doi:10.1029/2005JA011037, 2005.

Hajj, G. A. and L. J. Romans, Ionospheric electron density profiles obtained with the Global Positioning System: Results from the GPS/MET experiment, Radio Sci., 33, 175-190, doi:10.1029/97RS03183, 1998.

Hernandez-Pajares, M., J. M. Juan, and J. Sanz, Improving the Abel in version by adding ground GPS data to LEO radio occultations in the ionospheric sounding, Geophys. Res. Lett., 27, 2743-2746, doi:10.1029/2000GL000032, 2000.

Jakowski, N., A. Wehrenpfennig, S. Heise, C. Reigber, H. Lühr, L. Grünwaldt, and T. K. Meehan, GPS radio occultation measurements of the ionosphere from CHAMP: Early results, Geophys. Res. Lett., 29(10), 1457, doi:10.1029/2001GL014364, 2002.

Kuo, Y.-H., T.-K. Wee, S. Sokolovskij, C. Rocken, W. Schreiner, D. Hunt, and R. A. Anthes, Inversion and error estimation of GPS radio occultation data, J. Meteorol. Soc. Jpn., 82(1B), 507-531, 2004.

Lin, C. H., J. Y. Liu, C. C. Hsiao, C. H. Liu, C. Z. Cheng et al., Global ionospheric structure imaged by FORMOSAT3/COSMIC: Early results, Terr. Atmos. Ocean. Sci., 20, 171-179, doi:10.3319/TAO.2008.01.18.01(F3C), 2009.

McNamara, L. F., Quality figures and error bars for autoscaled Digisonde vertical incidence ionograms, Radio Sci., 41, RS4011, doi:10.1029/2005RS 003440, 2006.

Reinisch, B. W. and X. Huang, Deducing topside profiles and total electron content from bottomside ionograms, Adv. Space Res., 27(1), 23-30, 2001 .

Reinisch, B. W., X. Huang, I. A. Galkin, V. Paznukhov, and A. Kozlov, Recent advances in real-time analysis of ionograms and ionospheric drift measurements with digisondes, J. Atmos. Sol.-Terr. Phys., 67, 1054$1062,2005$.

Schreiner, W. S., S. V. Sokolovskiy, C. Rocken, and D. C. Hunt, Analysis and validation of GPS/MET radio occultation data in the ionosphere, Radio Sci., 34, 949-966, doi:10.1029/1999RS900034, 1999.

Syndergaard, S., W. S. Schreiner, C. Rocken, D. C. Hunt, and K. F. Dymond, Preparing for COSMIC: Inversion and analysis of ionospheric data products, in Atmosphere and Climate: Studies by Occultation Methods, edited by Foelsche, U., G. Kirchengast, and A. K. Steiner, pp. $137-$ 146, Springer, New York, 2006.

Tsai, L. C., C. H. Liu, T. Y. Hsiao, and C. C. Chang, Maps of ionospheric F2-layer haracteristics derived from GPS radio occultation observations, Terr. Atmos. Ocean. Sci., 20, 535-546, doi:10.3319/TAO.2008.07.07.02(AA), 2009.

I. E. Zakharenkova (e-mail: zakharenkova@mail.ru), A. Krankowski, I. I. Shagimuratov, Yu. V. Cherniak, A. Krypiak-Gregorczyk, P. Wielgosz, and A. F. Lagovsky 